\title{
A prospective study of percutaneous vertebroplasty for chronic painful osteoporotic vertebral compression fracture
}

\author{
Hong-Yu Tan MD, Li-Min Wang MD, Liang Zhao MD, Yi-Lin Liu MD, Rui-Peng Song MD
}

H-Y Tan, L-M Wang, L Zhao, Y-L Liu, R-P Song. A prospective study of percutaneous vertebroplasty for chronic painful osteoporotic vertebral compression fracture. Pain Res Manag 2015;20(1):e8e11.

BACKGROUND: Percutaneous vertebroplasty (PVP) for patients with chronic painful osteoporotic compression fractures has not been extensively studied.

OBJECTIVE: To prospectively evaluate the efficacy of PVP for patients with chronic painful osteoporotic vertebral compression fractures (VCFs). METHODS: Sixty-two consecutive patients with chronic painful osteoporotic VCFs for $\geq 3$ months underwent PVP. All procedures were performed under local anesthesia. The outcomes were pain relief at one week, one month, three months, six months and one year, as measured by visual analogue scale, Oswestry Disability Index, Quality of Life Questionnaire of the European Foundation for Osteoporosis (QUALEFFO) and Roland Morris Disability Questionnaire scores.

RESULTS: The PVP procedures were technically successful and well tolerated in all patients. Sixty-two patients underwent PVP on 92 vertebrae in 73 procedures three to five days after referral, and no 30-day mortality was observed. Compared with baseline scores, improvement in visual analogue scale, Oswestry Disability Index, QUALEFFO and Roland Morris Disability Questionnaire scores was significantly greater after PVP at one week $(P<0.001)$, one month $(P<0.001)$, three months $(P<0.001)$, six months $(\mathrm{P}<0.001)$ and one year $(\mathrm{P}<0.001)$, and the number of patients using drugs for pain treatment was significantly reduced. Five new fractures were reported in five of 62 patients treated with PVP during follow-up. CONCLUSION: PVP is effective in patients with chronic painful osteoporotic VCFs. Pain relief after PVP was immediate, was sustained for one year and may be an important factor for reducing persistent pain.

Key Words: Osteoporosis; Pain; Percutaneous vertebroplasty; Vertebral compression fracture

\author{
Une étude prospective de la vertébroplastie \\ prospective pour soigner des fractures de \\ compression vertébrale ostéoporotiques \\ douloureuses et chroniques
}

HISTORIQUE : La vertébroplastie percutanée (VPP) effectuée chez des
patients ayant des fractures de compression ostéoporotiques douloureuses
et chroniques n'est pas très étudiée. OBJECTIF : Faire une évaluation prospective de l'efficacité de la VPP chez les patients ayant des fractures de compression vertébrale (FCV) ostéoporotiques douloureuses et chroniques.

MÉTHODOLOGIE : Soixante-deux patients consécutifs ayant des FCV ostéoporotiques douloureuses et chroniques depuis au moins trois mois ont subi une VPP. Toutes les interventions ont été exécutées sous anesthésie locale. Les résultats cliniques étaient un soulagement de la douleur au bout d'une semaine, d'un mois, de trois mois, de six mois et d'un an, mesuré au moyen d'une échelle analogique visuelle, de l'indice d'Oswestry, du questionnaire sur la qualité de vie de la European Foundation for Osteoporosis (QUALEFFO) et des indices du questionnaire d'évaluation de l'incapacité de Roland Morris.

RÉSULTATS : La VPP était réussie sur le plan technique et bien tolérée chez tous les patients. Soixante-deux patients ont subi une VPP sur 92 vertèbres, dans le cadre de 73 interventions effectuées de trois à cinq jours après la consultation. La VPP ne s'associait à aucun décès observé au bout de 30 jours. Par rapport aux données de départ, les résultats de l'échelle analogique visuelle, de l'indice d'Oswestry, du QUALEFFO et des indices du questionnaire d'évaluation de l'incapacité de Roland Morris s'amélioraient beaucoup une semaine $(\mathrm{P}<0,001)$, un mois $(\mathrm{P}<0,001)$, trois mois $(\mathrm{P}<0,001)$, six mois $(\mathrm{P}<0,001)$ et un an $(\mathrm{P}<0,001)$ après la VPP, et le nombre de patients utilisant des médicaments pour soulager la douleur avait considérablement diminué. Au suivi, cinq nouvelles fractures ont été signalées chez cinq des 62 patients ayant subi une VPP.

CONCLUSION : La VPP est efficace chez les patients atteints de FCV ostéoporotiques douloureuses et chroniques. Le soulagement de la douleur était immédiat après la VPP, se maintenait pendant un an et pourrait être un important facteur de réduction des douleurs persistantes.
Dercutaneous vertebroplasty (PVP), which involves percutaneous injection of bone cement into the fractured vertebral body, is a widely accepted treatment for patients with painful vertebral compression fractures (VCFs) (1-12). The procedure results in substantial pain relief for most patients $(1,2)$. A recent systematic literature review demonstrated the effectiveness of PVP in $87 \%$ of patients in terms of pain relief as well as a short- and long-term improvement of physical function $(3,12)$.

PVP not only results in substantial pain relief but also provides the possibility to stabilize vertebral fractures by injecting a small quantity of bone cement into the collapsed vertebral body. However, PVP for patients with failure of conservative treatment, especially for chronic painful VCFs, has been less well studied $(13,14)$. Therefore, the purpose of the present study was to evaluate the efficacy of PVP for patients with chronic painful VCFs, focusing on pain relief, functional outcomes and stability of vertebral fractures.

\section{Study subjects}

\section{METHODS}

The institutional review board at The First Affiliated Hospital, Zhengzhou University, Zhengzhou, China, approved the study protocol and patients provided informed consent before participation. Between January 2007 and June 2011, patients with history of chronic painful VCFs $\geq 3$ months or more prospectively underwent PVP treatment.

The inclusion criteria for the present prospective study were as follows: patients $\geq 50$ years of age with definite history of VCF with back pain for at least three months (Figure 1); level of fracture between T5 and L5; visual analogue scale (VAS) score of $\geq 5$; focal tenderness at fracture level as assessed by an internist on physical examination; decreased bone density ( $T$ scores $\leq-1$ ); and clinical and imaging follow-up taken $\geq 12$ months after the initial treatment. Exclusion criteria were: severe cardiopulmonary comorbidity $(n=0)$; untreatable coagulopathy $(n=0)$; systemic or local

Department of Orthopaedics, The First Affiliated Hospital, Zhengzhou University, Zhengzhou, China

Correspondence: Dr Li-Min Wang, No.1, East Jian She Road, Zhengzhou, Henan Province, China 450052. Telephone 86-0371-66207209,

fax 86-0371-66207209, e-mail wanglmzz@163.com

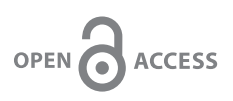

This open-access article is distributed under the terms of the Creative Commons Attribution Non-Commercial License (CC BY-NC) (http:// creativecommons.org/licenses/by-nc/4.0/), which permits reuse, distribution and reproduction of the article, provided that the original work is properly cited and the reuse is restricted to noncommercial purposes. For commercial reuse, contact support@pulsus.com 

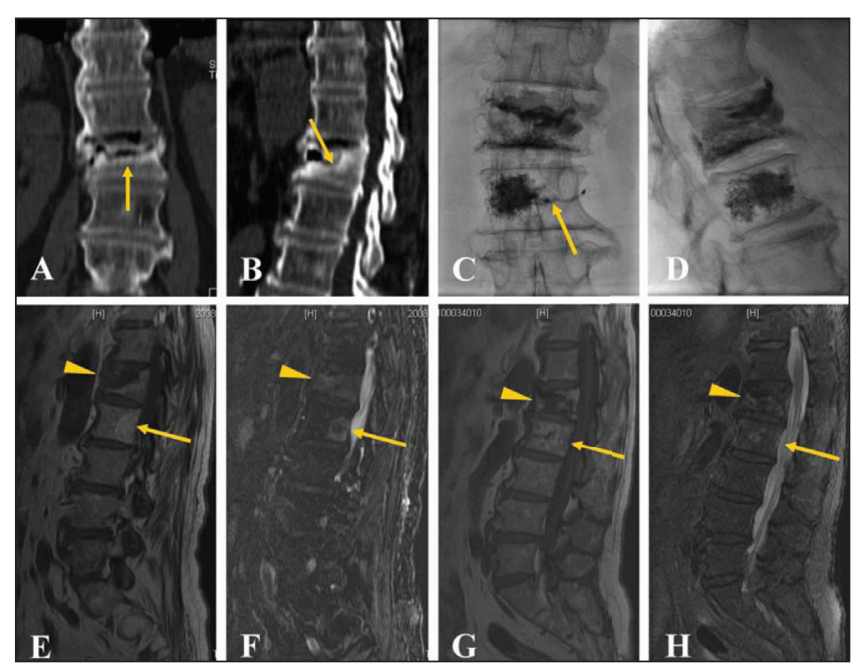

Figure 1) A 74-year-old male patient with persistent back pain and a visual analogue scale score of 7 for $>10$ months. Coronary (A) and sagittal (B) computed tomography reconstruction demonstrates a border of osteosclerosis at the fracture site (arrow). Anteroposterior (C) and lateral (D) plain films show bone cement injected into the L1 and L2 vertebral bodies with slight vein leakage (arrow) at the L2 level. Magnetic resonance imaging reveals low signal (arrowhead) on T1WI images (E) and high signal (arrowhead) on T2WI (F) at the L1 level before percutaneous vertebroplasty. Note also a hemangioma (arrow) at the $\mathrm{L} 2$ level. Magnetic resonance imaging displays low signal (arrowhead) on T1WI (G) and slightly high signal (arrowhead) on T2WI $(\mathrm{H})$ images at the $\mathrm{L} 1$ level one year after percutaneous vertebroplasty with stability of the vertebral body without obvious focal kyphosis

spine infection $(n=0)$; suspected underlying malignant disease $(n=0)$; radicular syndrome $(n=2)$; spinal cord compression syndrome $(n=3)$; and contraindication for magnetic resonance imaging (MRI) $(n=5)$.

A total of 77 patients with chronic painful VCFs were enrolled in the present study. Of these, 15 patients did not meet the inclusion criteria and were excluded from the study, with follow-up of $<12$ months in eight patients and follow-up loss in seven patients (four in the sixth month and three in 12 th month). The remaining 62 patients were enrolled. There were 22 men and 40 women with a mean age of $65.45 \pm 8.68$ years (range 51 to 83 years); demographic and clinical characteristics of these patients are summarized in Table 1.

\section{MRI protocol}

MRI was performed using a 1.5 or 3 Tesla MRI scanner (GE Medical Systems, USA). The following MRI sequences were employed: sagittal T1 (TR/TE, 400 ms/13 ms), T2 Spin Echo (TR/TE, 3500 ms/120 ms), STIR (TR/TE, $2500 \mathrm{~ms} / 70 \mathrm{~ms}$ ) and transverse T2 TSE (TR/TE, $2500 \mathrm{~ms} / 120 \mathrm{~ms}$ ) at the level of the affected VCF. The grade of VCF was classified, as a percentage of height reduction, as mild (15\% to $25 \%$ ), moderate ( $>25 \%$ to $40 \%$ ) and severe (>40\%) according to the grading system of Genant et al (15).

\section{Interventions}

PVP was performed by two of the orthopedic surgeons (HYT and LMW) who specialize in spine surgery, and was performed on a singleplane angiography system under fluoroscopic guidance. Blood pressure, heart rate, oxygen saturation and other vital signs were monitored using an electrocardiogram monitor during the procedure.

The patient was placed in a prone position on an operating table. After local anesthesia, a small dermatotomy incision was made with a scalpel blade. Thereafter, a bone puncture needle (13 G, Cook, USA) was placed transpedicularly in the fractured vertebral. After removal of the inner needle, commercially available polymethyl methacrylate (PMMA) (Osteo-Firm, COOK Medical, USA) was carefully injected into the fractured vertebral under continuous fluoroscopic monitoring via lateral and anteroposterior projections to ensure adequate lesion

\section{TABLE 1}

\section{Demographic and clinical characteristics of patients with} chronic osteoporotic vertebral fractures $(n=62)$

\begin{tabular}{lc}
\hline Characteristic & $65.45 \pm 8.68$ \\
\hline Age, years, mean \pm SD & $22 / 40$ \\
Male/female, $n / n$ & $7.0 \pm 2.78(3-13)$ \\
Duration of back pain, months, & \\
mean \pm SD (range) & $2.13 \pm 0.89(1-4)$ \\
Number of VCFs at baseline, & \\
mean \pm SD (range) & \\
Number and grading of VCFs & $11(17)$ \\
Mild (15\% to 25\%) & $42(68)$ \\
Moderate $(>25 \%$ to $40 \%)$ & $9(15)$ \\
Severe $>40 \%)$ & $49(79)$ \\
Wedge & $13(21)$ \\
Biconcave & $0(0)$ \\
Crush & \\
Initial pain treatment & $0(0)$ \\
None & $13(21)$ \\
Nonopiate drugs & $32(52)$ \\
Weak opiate derivatives & $17(27)$ \\
Strong opiate derivatives & $47(76)$ \\
Use of osteoporosis drugs & $-2.90 \pm 0.70$ \\
Bone density T score & \\
\hline
\end{tabular}

Data presented as $n$ (\%) unless otherwise indicated. VCF Vertebral compression fracture

filling, and to avoid PMMA leakage or migration into the venous system toward the lungs. Injection was ceased when substantial resistance was met or when the cement reached the cortical edge of the fractured vertebral body; injection was also stopped if cement leaked into extraosseous structures or veins. Postprocedural fluoroscopic evaluation was obtained to show optimal filling of the lesion with no evidence of PMMA extravasation. After the procedure, a computed tomography (CT) scan of the treated vertebral bodies was performed with $2 \mathrm{~mm}$ slices three to five days after PVP to identify the distribution of cement in the lesion, cement leakage outside the vertebral body or other possible local complications.

\section{Clinical outcome evaluation}

The patients were clinically examined by one of the authors, who gathered the initial and follow-up data before and at one day, one week and one, three, six and 12 months after the procedure. Imaging followup consisted of anteroposterior and lateral spinal $x$-ray examinations at one month, six months and one year after the procedure. MRI was performed in the same manner as before the procedures, at three month and one year after the procedure in all patients (Figure 1).

Data regarding the technical success, pain relief, Oswestry Disability Index (ODI), quality of life, physical function and complications were evaluated during the one year follow-up. Technical success was defined as successfully performed PVP without major complications.

The pain relief was measured using a VAS score ranging from 0 (no pain) to 10 (worst pain ever). The functional status of patients for walking, standing and sleeping was measured using the ODI (16). The ODI comprises a 10-item questionnaire on pain, personal care, lifting, walking, sitting, standing, sleeping, sex life, social life and travelling, with patients scoring each item on a scale from 0 (best possible state) to 5 (worst possible state). The quality of life was measured with the Quality of Life Questionnaire of the European Foundation for Osteoporosis (QUALEFFO) (17), and the physical function was measured with the Roland-Morris Disability (RMD) questionnaire (18). Standard questionnaires including additional questions about pain treatment, hospital stay, outpatient visits and medical aids were completed with the help of a nurse practitioner. 
Any complications following PVP, such as wound infections, nerve injuries, cement leakage and pulmonary embolism, were recorded.

\section{Statistical analysis}

Descriptive data are presented as means \pm SDs. Comparisons of preand postprocedure VAS and ODI scores were analyzed using nonparametric tests for paired samples, and the correlation was evaluated using the Wilcoxon signed-rank test. Significant pain relief over time was determined using the Kaplan-Meier method and the log-rank test was used to evaluate between-group differences. SPSS version 13.0 (IBM Incorporated, USA) was used for the analyses; $\mathrm{P} \leq 0.05$ was considered to be statistically significant.

\section{Primary procedural results}

The chronic osteoporotic VCFs before PVP and treated vertebrae post-PVP is summarized in Table 2. The PVP procedures were technically successful and well tolerated in all patients. Sixty-two patients underwent PVP on 92 vertebrae in 73 procedures that occurred three to five days after referral to the authors' department, with a technique successful rate of $100 \%$. All procedures were performed by the same two surgeons together. Forty-five patients had injections in single vertebra and 17 had injections in multiple vertebra (nine patients in two vertebrae, three patients in three and five patients in four). Fifty-one patients completed the procedures in a single session, whereas 11 patients required two sessions. Vertebroplasty was performed using a single pedicle technique in 25 patients and dual pedicle technique in the remaining 37 patients. The mean $( \pm \mathrm{SD})$ volume of injected cement per vertebral body was $3.6 \pm 1.3 \mathrm{~mL}$ (range $1 \mathrm{~mL}$ to $6 \mathrm{~mL}$ ). CT scanning showed cement leakage in $53(58 \%)$ of the 92 treated vertebral bodies. Most leakages were discal or into segmental veins; none were into the spinal canal. Fluoroscopy showed cement migration into the venous system toward the lungs in two patients (6.5\%); however, these patients remained asymptomatic without complications during follow-up. The mean postoperative hospitalization time for the procedure was 5.7 days (range three to eight days), and the 30-day mortality rate was zero.

\section{Follow-up results}

One-year follow-up were completed for all patients, and baseline and follow-up VAS, ODI, QUALEFFO and RMD scores are presented in Table 3. Compared with baseline scores, improvement in VAS, ODI, QUALEFFO and RMD scores were significantly greater after PVP at one week $(\mathrm{P}<0.001)$, one month $(\mathrm{P}<0.001)$, three months $(\mathrm{P}<0.001)$, six months $(\mathrm{P}<0.001)$ and one year $(\mathrm{P}<0.001)$.

After PVP, the number of patients using drugs for pain treatment was significantly reduced compared with baseline at one week $(\mathrm{P}<0.001)$, one month $(\mathrm{P}<0.001)$, three months $(\mathrm{P}<0.001)$, six months $(\mathrm{P}<0.001)$ and one year $(\mathrm{P}<0.001)$. In addition, five new fractures were reported by $\mathrm{x}$-ray and/or MRI in five of 62 patients treated with PVP during follow-ups.

\section{DISCUSSION}

Vertebral fractures are the most common complication of osteopenia, affecting 20\% of individuals $>70$ years of age. These fractures represent an important cause of disability and morbidity in elderly patients (19), and have a negative effect on life quality, physical function, mental health and survival (20). For patients with acute or subacute pain, conservative treatment offers satisfactory clinical results, with pain intensity reduction within a few weeks and a gradual recovery process within two or three months (21), while for patients with chronic osteoporotic vertebral fractures, satisfactory clinical results could not be obtained with conservative treatment; on the contrary, conservative treatment may result in persistent chronic back pain, instability of the spine, functional limitation, prolonged immobilization, worsening quality of life, decrease of bone mineral density, muscle hypotonia, mood impairment, depressive syndrome and higher mortality rate.
TABLE 2

\begin{tabular}{lcc}
\multicolumn{3}{c}{$\begin{array}{c}\text { Summary of the chronic osteoporotic vertebral } \\
\text { compression fractures (VCFs) before percutaneous } \\
\text { vertebroplasty (PVP) and treated vertebrae post-PVP }\end{array}$} \\
\hline Vertebrae & $\begin{array}{c}\text { Chronic osteoporotic } \\
\text { VCFs ( } \mathbf{n}=62)\end{array}$ & $\begin{array}{r}\text { Treated vertebrae* } \\
\text { (n=92) }\end{array}$ \\
\hline T3 & & 1 \\
T4 & 1 & 2 \\
T5 & 1 & 2 \\
T6 & 2 & 3 \\
T7 & 3 & 3 \\
T8 & 4 & 5 \\
T9 & 5 & 4 \\
T10 & 5 & 7 \\
T11 & 6 & 8 \\
T12 & 9 & 13 \\
L1 & 10 & 12 \\
L2 & 7 & 10 \\
L3 & 6 & 10 \\
L4 & 5 & 7 \\
L5 & 3 & 5 \\
\hline
\end{tabular}

*Includes acute or subacute osteoporotic VCFs in addition to chronic osteoporotic VCFs

In the present study, we aimed to evaluate the clinical results of PVP for patients with chronic painful VCFs. After PVP, pain relief was significant, and the number of patients who used drugs for pain was significantly reduced. Although minor cement leakage was frequently noted on CT scan, leakage was asymptomatic in all cases. With PVP, no serious complications occurred. This finding was consistent with other studies $(3,22)$. In addition, in our series, follow-up data also revealed that ODI scores, physical function and quality of life was maintained within satisfactory limits, and significantly improved ODI scores, physical function and quality of life were obtained in patients with chronic painful osteoporotic vertebral fractures $\geq 12$ months later. This finding was similar to those of Kaufmann et al (23). They had even reported that a fracture duration of up to one year was associated with a good response to PVP and benefit from mid-term pain relief, and good quality of life (23). These promising results indicate that PVP was not only an effective procedure, but also resulted in greater pain relief in patients with chronic osteoporotic vertebral fractures and persistent severe pain.

Recently, two randomized sham-controlled trials have been published comparing PVP with conservative therapy in patients with osteoporotic vertebral fractures up to one year of duration $(24,25)$. Both studies demonstrated similar results in pain and pain-related disability after a six-month follow-up. The sham-controlled studies differed in one important way from our study. In the present study, we focused on patients with failure of conservative treatment and chronic compression fractures with persistent severe pain for $\geq 3$ months, whereas the sham-controlled studies included patients with acute or subacute fractures for $<3$ months. Conservative treatment may offer satisfactory clinical results in most of the cases with acute or subacute fractures. However, a considerable number of patients with chronic compression fractures do not respond successfully to conservative treatment, and persistent chronic pain may result from incomplete vertebral healing due to further bone collapse; altered vertebral column kinematics subsequent to spinal deformity; or pseudoarthrosis of the fractured vertebral body (19). The difference may account for the small improvement in VAS score in the sham-controlled studies compared with our study.

Our study had several limitations. First, the number of patients was relatively small, and no control group was included; future randomized multicentre trials comparing the use of this approach with 
TABLE 3

Baseline and follow-up variables of percutaneous vertebroplasty

\begin{tabular}{lcccccc}
\hline Evaluation & Preprocedure & One week & One month & Three months & Six months & One year \\
\hline VAS score & $6.58 \pm 0.81$ & $3.39 \pm 0.56$ & $2.84 \pm 0.52$ & $2.77 \pm 0.62$ & $2.74 \pm 0.77$ & $2.77 \pm 0.72$ \\
ODI score & $58.77 \pm 2.36$ & $30.32 \pm 2.94$ & $20.74 \pm 3.11$ & $16.42 \pm 1.50$ & $15.55 \pm 1.09$ \\
QUALEFFO score & $57.45 \pm 3.03$ & $46.65 \pm 3.09$ & $44.87 \pm 2.75$ & $40.93 \pm 3.29$ & $39.93 \pm 2.57$ \\
RMD score & $18.16 \pm 2.0$ & $14.10 \pm 1.94$ & $12.35 \pm 1.45$ & $10.84 \pm 1.70$ & $10.03 \pm 1.35$ \\
Pain treatment, $n$ & 62 & 26 & 13 & 8 & $40.0 \pm 1.91$ \\
\hline
\end{tabular}

ODI Oswestry Disability Index; OQUALEFFO Quality of Life Questionnaire of the European Foundation for Osteoporosis; RMD Roland-Morris Disability; VAS Visual analogue scale

conservative treatment are needed to evaluate the mid- and long-term clinical efficacy, and the risk of complications involved in the treatment of patients with chronic osteoporotic vertebral fractures and persistent pain. Second, cement leakage outside the vertebral body may occur in patients with chronic osteoporotic VCFs; therefore, fluoroscopy from multiple angles should be routinely performed during the procedure to avoid possible complications.

\section{REFERENCES}

1. Klazen CA, Lohle PN, de Vries J, et al. Vertebroplasty versus conservative treatment in acute osteoporotic vertebral compression fractures (Vertos II): An open-label randomised trial. Lancet 2010;376:1085-92.

2. Evans AJ, Jensen ME, Kip KE, et al. Vertebral compression fractures: Pain reduction and improvement in functional mobility after percutaneous polymethylmethacrylate vertebroplasty retrospective report of 245 cases. Radiology 2003;226:366-72.

3. Hulme PA, Krebs J, Ferguson SJ, Berlemann U. Vertebroplasty and kyphoplasty: A systematic review of 69 clinical studies. Spine 2006;31:1983-2001.

4. Zoarski GH, Snow P, Olan WJ, et al. Percutaneous vertebroplasty for osteoporotic compression fractures: Quantitative prospective evaluation of long-term outcomes. J Vasc Interv Radiol 2002;13:139-48.

5. McGraw JK, Lippert JA, Minkus KD, Rami PM, Davis TM, Budzik RF. Prospective evaluation of pain relief in 100 patients undergoing percutaneous vertebroplasty: Results and follow-up. J Vasc Interv Radiol 2002;13:883-6.

6. Legroux-Gérot I, Lormeau C, Boutry N, Cotten A, Duquesnoy B, Cortet B. Long-term follow-up of vertebral osteoporotic fractures treated by percutaneous vertebroplasty. Clin Rheumatol 2004:23:310-7.

7. Voormolen MH, Lohle PN, Lampmann LE, et al. Prospective clinical follow-up after percutaneous vertebroplasty in patients with painful osteoporotic vertebral compression fractures. J Vasc Interv Radiol 2006;17:1313-20.

8. Anselmetti GC, Corrao G, Monica PD, et al. Pain relief following percutaneous vertebroplasty: Results of a series of 283 consecutive patients treated in a single institution. Cardiovasc Intervent Radiol 2007;30:441-7.

9. Alvarez L, Alcaraz M, Pérez-Higueras A, et al. Percutaneous vertebroplasty: Functional improvement in patients with osteoporotic compression fractures. Spine 2006;31:1113-8.

10. Ploeg WT, Veldhuizen AG, The B, Sietsma MS. Percutaneous vertebroplasty as a treatment for osteoporotic vertebral compression fractures: A systematic review. Eur Spine J 2006;15:1749-58.

11. Rousing R, Hansen KL, Andersen MO, Jespersen SM, Thomsen K, Lauritsen JM. Twelve-months follow-up in forty-nine patients with acute/semiacute osteoporotic vertebral fractures treated conservatively or with percutaneous vertebroplasty: A clinical randomized study. Spine 2010;35:478-82.

12. McGirt MJ, Parker SL, Wolinsky JP, Witham TF, Bydon A, Gokaslan ZL. Vertebroplasty and kyphoplasty for the treatment of

\section{CONCLUSION}

Although further clinical trials and expanded follow-up studies are needed, our study proved that PVP is effective in patients with chronic painful VCFs and failure of conservative treatment. Pain relief after PVP is immediate, sustained for one year, and may be an important factor for reducing persistent pain.

DISCLOSURES: The authors have no conflicts of interest to declare.

vertebral compression fractures: An evidenced-based review of the literature. Spine J 2009;9:501-8.

13. Brown DB, Glaiberman CB, Gilula LA, Shimony JS. Correlation between preprocedural MRI findings and clinical outcomes in the treatment of chronic symptomatic vertebral compression fractures with percutaneous vertebroplasty. AJR Am J Roentgenol 2005;184:1951-5.

14. Brown DB, Gilula LA, Sehgal M, Shimony JS. Treatment of chronic symptomatic vertebral compression fractures with percutaneous vertebroplasty. AJR Am J Roentgenol 2004;182:319-22.

15. Genant HK, Wu CY, van Kuijk C, Nevitt MC. Vertebral fracture assessment using a semiquantitative technique. J Bone Miner Res 1993;8:1137-48.

16. Fairbank J, Pynsent P. The Oswestry Disability Index. Spine 2000;25:2940-53.

17. Lips P, Cooper C, Agnusdei D, et al. Quality of life in patients with vertebral fractures: Validation of the Quality of Life Questionnaire of the European Foundation for Osteoporosis (QUALEFFO). Osteoporos Int 1999;10:150-60.

18. Roland M, Morris R. A study of the natural history of low-back pain. Part II: Development of guidelines for trials of treatment in primary care. Spine 1983;8:145-50.

19. Phillips FM. Minimally invasive treatments of osteoporotic vertebral compression fractures. Spine 2003;28:S45-S53.

20. Silverman SL. The clinical consequences of vertebral compression fracture. Bone 1992;13:S27-S31.

21. Shen WJ, Shen YS. Nonsurgical treatment of three-column thoracolumbar junction burst fractures without neurologic deficit. Spine 1999;24:412-5.

22. Eck JC, Nachtigall D, Humphreys SC, Hodges SD. Comparison of vertebroplasty and balloon kyphoplasty for treatment of vertebral compression fractures: A meta-analysis of the literature. Spine J 2008;8:488-97.

23. Kaufmann TJ, Jensen ME, Schweickert PA, Marx WF, Kallmes DF. Age of fracture and clinical outcomes of percutaneous vertebroplasty. AJNR Am J Neuroradiol 2001;22:1860-3.

24. Buchbinder R, Osborne RH, Ebeling PR, et al. A randomized trial of vertebroplasty for painful osteoporotic vertebral fractures. N Engl J Med 2009;361:557-68.

25. Kallmes DF, Comstock BA, Heagerty PJ, et al. A randomized trial of vertebroplasty for osteoporotic spinal fractures. $\mathrm{N}$ Engl J Med 2009;361:569-79. 


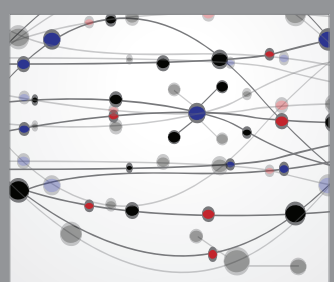

The Scientific World Journal
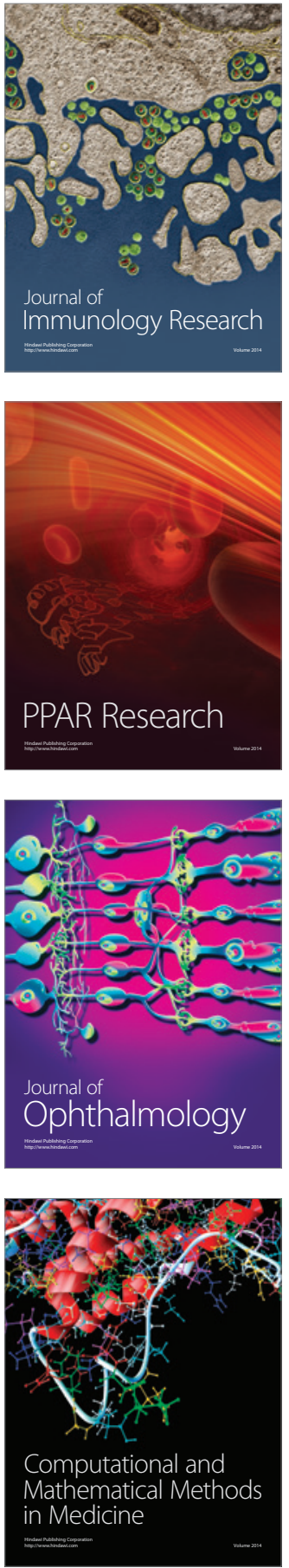

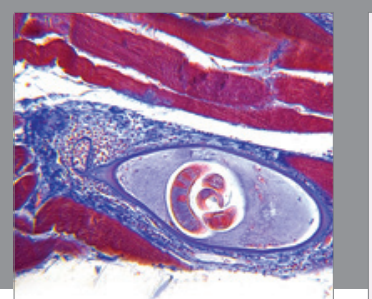

Gastroenterology Research and Practice

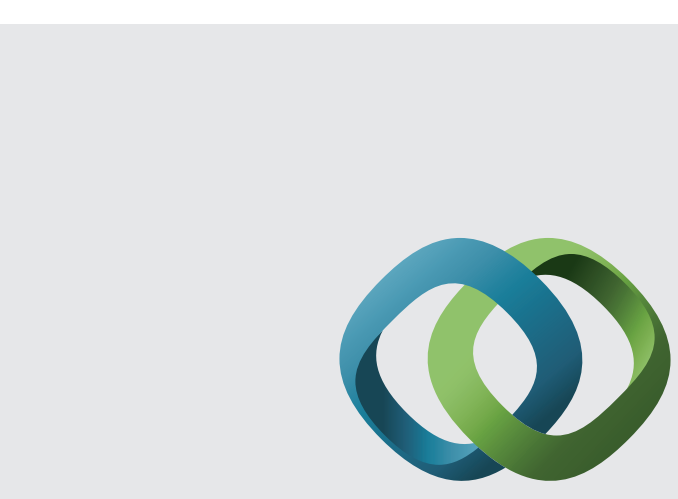

\section{Hindawi}

Submit your manuscripts at

http://www.hindawi.com
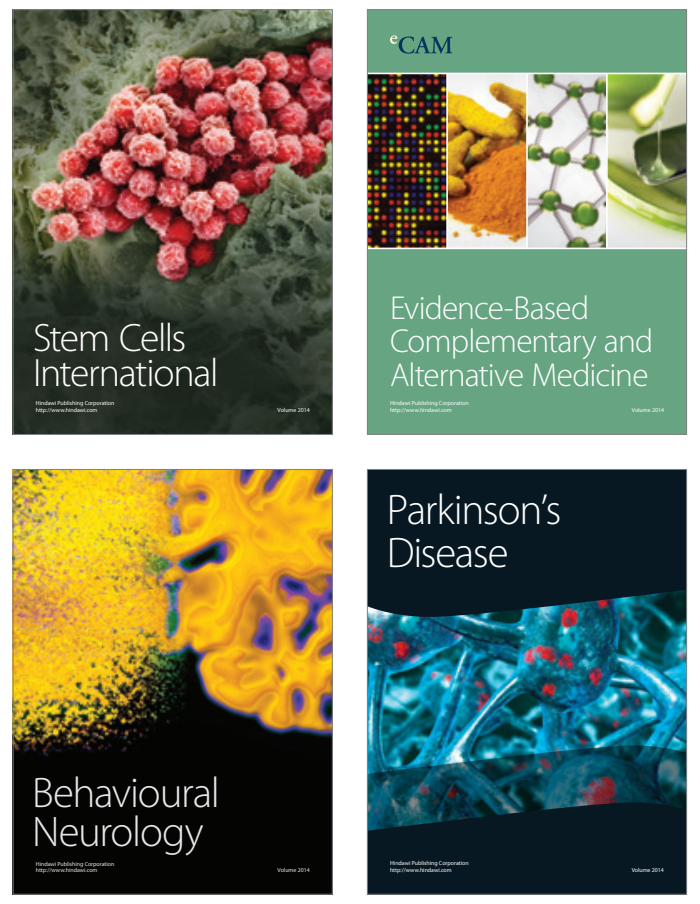
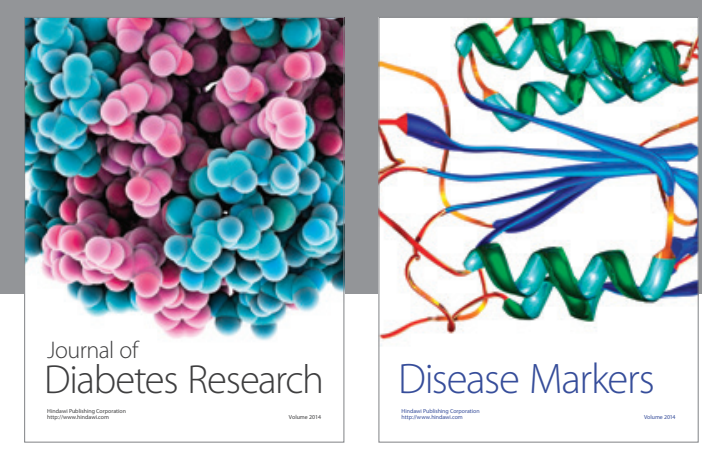

Disease Markers
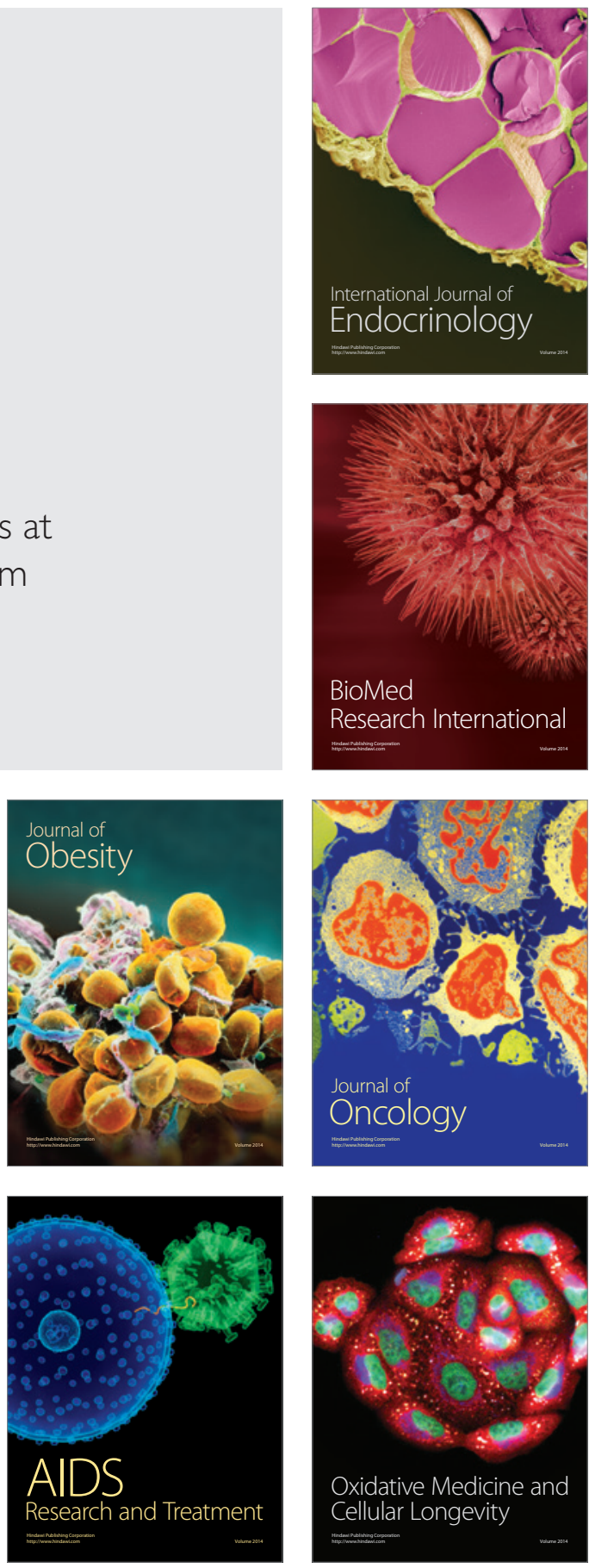